\title{
Apego e adolescência institucionalizada: estudo de caso
}

\author{
Attachment and institutionalized adolescence: a case study
}

Eloísa Cerutti Martellet ${ }^{[a]}$, Aline Cardoso Siqueira ${ }^{[b]}$

\footnotetext{
${ }^{[a]}$ Graduada em Psicologia pelo Centro Universitário Franciscano (Unifra), Santa Maria, RS - Brasil, e-mail:

eloisa.cerutti@hotmail.com

${ }^{[b]}$ Doutora em Psicologia, docente do Departamento de Psicologia na Universidade Federal de Santa Maria (UFSM), Santa Maria, RS Brasil, e-mail: alinesiq@gmail.com
}

Recebido: 24/01/2012 Received: 01/24/2012

Aprovado: 05/06/2012 Approved: 06/05/2012

\section{Resumo}

O desenvolvimento do apego em adolescentes em acolhimento institucional pode ser influenciado pelas rupturas de vínculo e vivência de diversos tipos de violência na infância. Apesar do reconhecido impacto que tais experiências trazem para as relações interpessoais, poucos estudos sobre apego na adolescência têm sido conduzidos. A maior parte das pesquisas possui o enfoque na infância, mesmo havendo muitos adolescentes em situação de acolhimento. Tendo como base a Teoria do Apego e a Teoria Bioecológica do Desenvolvimento Humano, o objetivo desse estudo foi compreender o processo de desenvolvimento do apego de uma adolescente em acolhimento institucional. A pesquisa possui caráter qualitativo, cujo delineamento foi o estudo de caso único, tendo como participante uma adolescente de 14 anos que viveu numerosas rupturas de vínculo na infância. Os dados foram obtidos através da triangulação das informações coletadas em entrevistas semiestruturadas realizadas com a adolescente, com uma familiar desta adolescente e com a psicóloga da instituição de acolhimento, como também da inserção ecológica. Evidências de que a adolescente possui o padrão de apego inseguro resistente desde a infância foram encontradas, corroborando a tendência de que há uma estabilidade no padrão de apego desenvolvido na infância. Contudo, os dados também apontaram que mudanças estão ocorrendo na adolescente a partir dos investimentos que o microssistema institucional vem operando, promovendo processos proximais e a possibilidade de alteração do padrão de apego no desenvolvimento na infância. Torna-se importante qualificar ainda mais o ambiente institucional, capacitando os educadores no que diz respeito a seu papel fundamental na relação com os adolescentes acolhidos.

Palavras-chave: Apego. Adolescência. Acolhimento institucional.

\begin{abstract}
The development of attachment in adolescents in institutional foster care may be influenced by the disruption of bonding and experiencing different forms of violence in childhood. Despite the recognized impact that such experiences bring to interpersonal relationships, few studies on attachment in adolescence have been conducted. Most of the researches focus on the child, even though there are many adolescents in foster care. Based on the Attachment Theory and the
\end{abstract}


Bioecological Theory of Human Development, the aim of this study was to understand the development process of attachment of a teenager in institutional care. The research has a qualitative approach, whose design was a single case study, and as a participant a 14 year old girl who lived numerous disruptions of attachment in childhood. Data were obtained by triangulating the information collected in semi-structured interviews with the adolescent, with a family member of this teenager and with the psychologist of the institution, as well as ecological engagement. Evidence that the adolescent has the insecure resistant attachment standard since childhood were found, corroborating the trend that there is stability in attachment pattern developed in childhood. However, the data also indicated that changes are occurring in the adolescent from the investments that the institutional microsystem has been operating, promoting proximal processes and the possibility of change in the pattern of attachment in childhood development. It becomes important to qualify the institutional environment even further, capacitating educators regarding their crucial role in the relations with the hosted adolescents.

Keywords: Attachment. Adolescence. Institutional care.

\section{Introdução}

O desenvolvimento do apego em adolescentes em acolhimento institucional por situação de risco é uma temática de grande relevância social, contudo, pouco investigada pelos pesquisadores brasileiros. A maior parte das pesquisas sobre este tema possui o enfoque na infância, mesmo havendo grande número de adolescentes em situação de acolhimento no Brasil, conforme demonstrado por Silva (2004). 0 acolhimento institucional é uma medida de proteção prevista no Estatuto da Criança e do Adolescente (ECA) (Brasil, 1990) para acolher crianças e adolescentes cujos direitos são ameaçados ou violados. Entre os principais motivos para o acolhimento institucional está a violência doméstica (Roing \& Ochotorena, 1993), sendo reconhecida como um aspecto influente para o desenvolvimento do apego (Oriente \& Souza, 2005).

0 termo "acolhimento institucional" é recente, foi proposto pela Lei 12.010, em 2009, no lugar dos termos "abrigo" ou "abrigamento". Abaid, Siqueira e Dell'Aglio (2012) e Ferreira, Dói e Baldacim (2009) apresentam e discutem as principais modificações que a Lei 12.010 realizou no ECA, como a determinação de um tempo de acolhimento máximo de dois anos (Brasil, 2009). A ideia determinista de que toda institucionalização abre um campo favorável para o surgimento de problemas biopsicossociais por causa do tratamento massificado, privação da convivência familiar, separação da figura de apego e confinamento social tem se enfraquecido após a implementação do ECA e das mudanças ocorridas no funcionamento institucional (Carvalho, 2002).

O desenvolvimento social, cognitivo e emocional de crianças e adolescentes que vivem em acolhimentos institucionais tem sido estudado por vários pesquisadores na atualidade (Alexandre \& Vieira, 2004; Dalbem, 2005; Dalbem \& Dell'Aglio, 2008; Dell'Aglio, 2000; Dell'Aglio \& Hutz, 2002; 2004; Martins \& Szymanski, 2004; Mota \& Matos, 2008; Pasian \& Jacquemin, 1999; Pereira et al., 2010; Prada, Williams, \& Weber, 2007; Siqueira \& Dell'Aglio, 2006; Siqueira, Spath, Dell'Aglio, \& Koller, 2011; Vectore \& Carvalho, 2008). Alguns estudos demonstram aspectos negativos encontrados no ambiente institucional e que refletem em piores índices de desenvolvimento, ao passo que outros estudos apresentam as possibilidades de saúde oferecidas pelas entidades de acolhimento, não havendo convergência entre os achados (Siqueira \& Dell'Aglio, 2006).

A Teoria do Apego, desenvolvida por Jonh Bowlby (1907-1990), fornece embasamento teórico para compreender aspectos do desenvolvimento emocional das crianças, bem como mecanismos utilizados em casos de trauma, perda ou rejeição pela figura de apego, questões comuns em sujeitos que se encontram em situação de risco. 0 apego é definido como uma variação do vínculo afetivo, no qual existe a busca e a manutenção da proximidade do outro, cuja presença ocasiona um acréscimo na sensação de segurança. No apego, o outro é visto como uma base segura, a partir da qual o indivíduo pode explorar o mundo e experimentar outras relações (Bowlby, 1990).

Na Teoria do Apego, o cuidador primário recebe um destaque especial, na medida em que a primeira relação de apego da criança vai se formar inicialmente em relação a esta figura, a qual é chamada de "figura de apego". Geralmente, a figura principal de apego é desempenhada pela mãe, posteriormente, 
pelo pai ou por outro familiar que atuará no papel de cuidador secundário. Há outras figuras a quem a criança pode manifestar o comportamento de apego posteriormente, chamadas "figuras subsidiárias de apego" (Ibid.). Estas primeiras relações são apontadas como cruciais para a definição dos tipos de padrão de vinculação que ocorrerão durante o desenvolvimento. 0 modelo de apego que um indivíduo desenvolve durante a primeira infância e adolescência é influenciado pela maneira como os cuidadores primários o trata e este modelo tende a se repetir durante toda a vida (Ibid.). Para o desenvolvimento do apego, duas variáveis são significativas: a sensibilidade da mãe ou cuidador responsável em responder aos sinais do seu bebê e a quantidade e natureza da interação entre a mãe e o bebê. Para entender os padrões de comportamento de apego e as condições que dão sua origem é necessário considerar um amplo sistema do qual o comportamento de apego faz parte e as variações em padrões de interação que ocorrem entre o par composto por mãe (cuidador principal) e bebê. Uma criança apega-se a figuras que atendam suas necessidades corporais, mas principalmente que interagem socialmente com ela. Por isso, para avaliar os padrões de apego é necessário que se faça referência aos padrões de cuidado materno. A partir dessa primeira relação, estabelece-se no indivíduo um modo de funcionamento, o "Modelo Funcional Interno", no qual o padrão de apego desenvolvido nos primeiros anos de vida influencia a forma que o indivíduo verá o mundo e si próprio. Em decorrência disso, as primeiras relações entre o bebê e seu cuidador principal são tão importantes para o desenvolvimento emocional do indivíduo.

Bowlby (1990) menciona o estudo de Ainsworth e colaboradores, que definiu três padrões diferentes de apego: apego seguro, apego inseguro esquivo e apego inseguro resistente. 0 apego seguro pode ser constatado quando a criança demonstra ser ativa nas brincadeiras, busca contato com a mãe após uma separação breve e é confortada com facilidade, voltando a se envolver em suas brincadeiras. 0 apego inseguro esquivo pode ser observado quando a criança, após uma breve separação da mãe, evita se reunir com ela quando de sua volta. Já o apego inseguro resistente é verificado quando a criança demonstra uma oscilação entre a busca de contato com sua mãe e a resistência ao contato com esta, além de mostrar-se mais colérica ou passiva do que as crianças com os padrões de apego anteriormente descritos.

No que se refere aos estudos sobre apego e vinculação das crianças e adolescentes no ambiente institucional, para Bowlby (1981), o desenvolvimento emocional de crianças institucionalizadas pode ser prejudicado pelas condições de risco as quais são expostas ou pela ausência materna, causando danos significativos, tanto físicos quanto mentais. Contudo, Bowlby (1981) afirma que a presença de uma figura materna, mesmo provisória e substituta, minimiza os efeitos nocivos da privação, pois possibilita a existência de uma relação afetiva, contribuindo para a saúde mental das crianças. Em situações graves na família, a instituição mostra-se como uma das melhores opções de apoio e afeto para o jovem afastado da família (Dell'Aglio, 2000).

0 estudo de Pereira et al. (2010), ao investigar o desenvolvimento mental e a qualidade do funcionamento socioemocional de crianças em instituições de Portugal, encontrou que, embora haja exposição precoce e prolongada à privação de cuidados familiares, muitas crianças não manifestam distúrbios no nível do apego. Para Alexandre e Vieira (2004), na falta de adultos que assumam papel significativo de referência afetiva, as crianças em situação de institucionalização acabam formando relações de apego umas com as outras. Nesse estudo, os autores encontraram responsividade por parte dos irmãos mais velhos direcionada aos mais novos no que se refere às solicitações de afeto e cuidado e interações afetivas durante atividades lúdicas. Estes aspectos podem mitigar os efeitos nocivos que a privação familiar pode causar no desenvolvimento do apego nas crianças, inclusive incrementando os processos de resiliência das crianças que se encontram em instituições.

Na adolescência, as questões relacionadas ao apego podem mudar. Outros adultos ou até mesmo pessoas da mesma idade podem passar a assumir importância igual ou maior a que antes era ocupada pelos pais ou figuras principais de apego. Bowlby (1990) afirma que a maior parte dos adolescentes, no entanto, permanece apegada aos pais e adquire novas figuras, podendo ser até mesmo instituições ou grupos de trabalho, religiosos ou políticos. $\mathrm{Na}$ vida adulta, o comportamento de apego se dá como uma continuação do existente na infância. Em situações delicadas, os adultos tornam-se mais exigentes em relação a outras pessoas e buscam aproximação 
em uma pessoa conhecida e de confiança, mostrando que o comportamento de apego se faz presente durante todo o ciclo vital (Bowlby, 1990).

Ainda é escassa a literatura brasileira que focaliza o estudo do apego em adolescentes institucionalizados. Além disso, os achados mais uma vez não são convergentes, pois uns demonstram a presença estável de apego inseguro e outros afirmam não ter encontrado apego inseguro entre os adolescentes pesquisados (Alexandre \& Vieira, 2004; Dalbem \& Dell'Aglio, 2008). Sabe-se que, na trajetória dos jovens institucionalizados, é encontrada a vivência de violência, negligência, abandono e afastamento familiar, entre outras situações de risco, aspectos que podem acarretar na dificuldade de relacionar-se com outras pessoas. Em pesquisa realizada com adolescentes institucionalizados, Dalbem e Dell'Aglio (2008) encontraram nos participantes a predominância da representação do padrão de apego inseguro, corroborando estudos internacionais (Hortacsu \& Cesur, 1993; Marcovitch et al., 1997). No entanto, segundo as autoras, a existência do padrão inseguro não impede que novas formas de vinculação sejam estabelecidas desde que haja um investimento da instituição em promover a capacidade de relacionar-se de forma saudável, com disponibilidade de apego mútuo, construindo relações de confiança e disponibilidade afetiva.

Embora estudos tenham afirmado que as interações no ambiente institucional podem proporcionar relações estáveis e possibilitar a reconstrução do padrão de apego, Vectore e Carvalho (2008) apresentam aspectos da rotina das casas-lares investigadas que poderiam dificultar este processo, como frequente ruptura do vínculo entre as mães sociais e a criança em decorrência da mudança de crianças de uma casa para outra, do desligamento da mãe social e da criança da instituição. Além disso, as autoras ainda problematizam a ideia encontrada de que afeto demasiado direcionado às crianças poderia comprometer o desligamento da criança, tanto quando ela é adotada quanto quando retorna para a família de origem. Estes dados corroboram a ideia de que, apesar de possível, a modificação de um padrão de apego atípico pode ainda não ser realidade para os jovens em situação de institucionalização (Mota \& Matos, 2008).

Para embasar a realização da pesquisa, a Teoria Biecológica do Desenvolvimento Humano (TBDH) foi utilizada no planejamento e na execução desse estudo. Este arcabouço teórico preconiza que o estudo do desenvolvimento humano seja realizado no contexto no qual o fenômeno ocorre, aspecto que garantiria validade ecológica ao estudo (Bronfenbrenner, 1986; 1979/1996; 2005). A TBDH, proposta por Bronfenbrenner em 1979, compreende o desenvolvimento humano a partir da interação de quatro importantes aspectos: pessoa, processo, contexto e tempo (PPCT), chamando-o de modelo bioecológico (Bronfenbrenner, 1986, 2005; Bronfenbrenner \& Morris, 1998; Bronfenbrenner \& Evans, 2000). 0 primeiro núcleo refere-se às características individuais, físicas e psicológicas da pessoa, aspectos cruciais para a relação desse indivíduo com seu mundo social.

O processo, segundo núcleo do modelo, é considerado o principal mecanismo responsável pelo desenvolvimento, sendo visto através de interações recíprocas, progressivamente mais complexas, de um ser humano ativo, biopsicologicamente em evolução com as pessoas, objetos e símbolos de seu ambiente imediato (Bronfenbrenner, 2005; Bronfenbrenner \& Morris, 1998). Chama-se de processos proximais as formas de interação complexas e recíprocas, nas quais o indivíduo encontra-se engajado na atividade em seu ambiente imediato, sendo necessário para o desenvolvimento das capacidades biológicas e do potencial genético de um indivíduo, pois possibilita que os recursos da pessoa sejam estimulados e desenvolvidos (Bronfenbrenner \& Ceci, 1994). Para que os processos proximais se estabeleçam, são necessários cinco aspectos: (1) a pessoa deve estar engajada em uma atividade; (2) esta atividade deve acontecer em uma base relativamente regular, através de períodos estendidos de tempo; (3) as atividades devem ser progressivamente mais complexas; (4) deve haver reciprocidade nas relações interpessoais; (5) os objetos e símbolos presentes no ambiente imediato devem estimular a atenção, exploração, manipulação e imaginação da pessoa em desenvolvimento (Bronfenbrenner, 1999).

0 terceiro núcleo corresponde ao contexto no qual o desenvolvimento ocorre, as pessoas presentes e seus papéis. É analisado através da interação dos quatro níveis ambientais: microssistema, mesossistema, exossistema e macrossistema. Estes níveis ambientais constituem o ambiente ecológico do indivíduo em desenvolvimento. 0 último elemento descrito pelo modelo bioecológico é o tempo, que atribui valor crucial às continuidades $\mathrm{e}$ 
descontinuidades na trajetória de vida ao longo de um período e propõe analisar a influência de mudanças e continuidades que acontecem ao longo da vida para o desenvolvimento humano (Bronfenbrenner, 1986). Assim, estes elementos teóricos da TBDH nortearam do planejamento à análise do caso, considerando as características individuais da adolescente, os processos proximais envolvidos na construção de seu padrão de apego, as características dos contextos de seu ambiente ecológico e a visualização da linha do tempo de sua vida na construção do padrão de apego.

Considerando a carência de estudos que abordam esse tema entre adolescentes e a importância de aprofundar o conhecimento no campo do desenvolvimento do apego em indivíduos nessa etapa de vida, torna-se fundamental desenvolver estudos sobre esta temática. A partir de estudos atuais e do embasamento teórico da Teoria do Apego e da Teoria Bioecológica do Desenvolvimento Humano (Bronfenbrenner, 1979/1996, 2005), o objetivo desse estudo foi compreender o processo de desenvolvimento do apego de uma adolescente em acolhimento institucional.

\section{Método}

\section{Delineamento e participantes}

A pesquisa possui caráter qualitativo, cujo delineamento foi o estudo de caso único (Yin, 2003/2005). 0 estudo foi realizado com uma adolescente de 14 anos que morava em um acolhimento institucional governamental na cidade de Santa Maria, RS. Ela foi acolhida por estar em situação de rua e exploração sexual, ficando no acolhimento por um ano e sete meses. Os critérios de inclusão da pesquisa eram ser adolescente, estar em acolhimento institucional há pelo menos seis meses e apresentar histórico de rupturas de vínculo na infância. Os critérios de exclusão do estudo eram apresentar atraso cognitivo significativo que impedisse a compreensão das questões da entrevista e ter diagnóstico de psicopatologia grave, o que demonstraria fragilidade egoica. Esta adolescente foi indicada pela equipe técnica do acolhimento por cumprir os critérios estabelecidos.

Para a apresentação do caso, serão utilizados nomes fictícios com o intuito de respeitar e preservar a identidade dos envolvidos. Para a participante foi dado o nome fictício de Verônica, para a sua irmã mais velha, de Mariana, para a segunda irmã, de Helena, para a psicóloga da instituição, de Suzana e para a avó, de Joana.

\section{Instrumentos}

Os instrumentos utilizados para mapear as relações de apego antigas e atuais da adolescente foram entrevistas semiestruturadas realizadas com a adolescente, com um familiar e com a psicóloga da instituição. As entrevistas realizadas com o familiar e com a psicóloga da instituição tinham questões sobre a história da infância e o processo de institucionalização da participante. Já a entrevista com a adolescente foi adaptada de um roteiro de entrevista realizado para investigação do Apego elaborado por Dalbem (2005).

\section{Procedimentos e consideracões éticas}

Foram respeitados todos os aspectos éticos relacionados à realização de pesquisas com seres humanos, conforme preconizam as Diretrizes e Normas de Pesquisas em Seres Humanos, segundo a Resolução 1996 do Conselho Nacional de Saúde (Brasil, 1997). Primeiramente, foi encaminhado à instituição de acolhimento o termo de concordância contendo as informações referentes à pesquisa. Após autorização da instituição, o projeto foi encaminhado ao Comitê de Ética em Pesquisa com Seres Humanos (CEP) do Centro Universitário Franciscano, sendo aprovado com o número de registro 143.2010.3.

Foi realizada uma inserção ecológica no campo de investigação. 0 procedimento teórico-metodológico da inserção ecológica, desenvolvido por Cecconello e Koller (2003) e revisado por Prati et al. (2008), consiste na sistematização do modelo bioecológico para a realização de pesquisas. Considerando os pressupostos desse procedimento, foram realizadas visitas periódicas e regulares na instituição de acolhimento, observações de atividades de sua rotina, conversas informais com educadores, técnicos do acolhimento e outras crianças e adolescentes, além de três encontros grupais com as adolescentes acolhidas no momento. Estes encontros tiveram como finalidade aproximar a 
pesquisadora das adolescentes, fazendo que elas se conhecessem, além de apresentar a pesquisa, seus procedimentos e objetivos. Todas as informações advindas da inserção ecológica foram registradas no diário de campo da pesquisadora e serviram de material para análise.

Somente após a aquisição das duas autorizações e de um período de dois meses de inserção ecológica a pesquisa foi apresentada à participante, que assinou o Termo de Consentimento Livre e Esclarecido. 0 familiar e a psicóloga também assinaram o Termo de Consentimento Livre e Esclarecido. Todos os aspectos éticos foram garantidos aos envolvidos na pesquisa, como sigilo, confidencialidade e possibilidade de desistir da pesquisa em qualquer momento da coleta de dados. Além disso, a pesquisadora estava preparada para identificar sentimentos e emoções negativas que fossem suscitados pela pesquisa e, caso isso acontecesse, ela interromperia a entrevista e comunicaria a equipe técnica do acolhimento, tendo em vista que ela já estava em atendimento psicológico. Vale salientar que não houve nenhum episódio que necessitasse tal interrupção. Entre os benefícios, pode-se pensar que a participação na pesquisa possibilitou que a adolescente verbalizasse aspectos primordiais de sua vida, o que pode ter trazido conforto e possibilidade de superação de dificuldades enfrentadas.

Com exceção da entrevista realizada com o familiar, que ocorreu no Laboratório de Práticas Psicológicas do curso de Psicologia do Centro Universitário Franciscano, todas as outras coletas ocorreram na instituição de acolhimento em que a adolescente estava. Foram realizadas 14 visitas ao acolhimento institucional. As entrevistas realizadas com a participante, a psicóloga e o familiar foram gravadas, transcritas para análise qualitativa dos dados e, posteriormente, destruídas.

\section{Resultados}

Verônica, 14 anos, era estudante da $6^{\underline{a}}$ série do ensino fundamental. Segundo dados da inserção ecológica, foi possível perceber que ela tinha uma personalidade forte, desafiadora, como se precisasse se impor no mundo. Ela era órfã de mãe com pai desconhecido. Era a quinta filha de seis irmãos, sendo três irmãs e dois irmãos. No entanto, mantinha contato, por determinação judicial, com apenas uma de suas irmãs, Helena, dez anos mais velha do que Verônica. De acordo com Helena e Suzana, psicóloga da instituição, Verônica possui uma história de abandono, violência e constantes rupturas de vínculo na infância.

Mesmo sem existir registros oficiais arquivados no acolhimento institucional nem informações completas tanto da perspectiva da irmã da adolescente quanto da atual equipe técnica, como a idade dos familiares, o número, tempo e as datas de todos os acolhimentos, foi possível estimar cronologicamente estas informações da história de vida de Verônica. Desde seu nascimento até os três anos de idade, Verônica morou com a mãe, os irmãos e o padrasto, mas era cuidada por Helena e por sua avó, Joana, que foi responsável pela criação de Helena. Neste período, segundo relatos das entrevistadas, Verônica sofria agressões físicas e maus tratos constantemente por parte de sua mãe. Ela era amarrada a uma cadeira e violentada fisicamente com a justificativa de ser uma criança difícil.

Após a morte de sua mãe, Verônica, então com cerca três anos de idade, passou a morar com sua tia, irmã de sua mãe, na cidade de Porto Alegre, RS. $\mathrm{Na}$ ocasião, nenhum familiar teve interesse em assumir sua guarda, mas como esta tia havia registrado sua irmã mais nova, Verônica foi morar com elas.

Conforme relato da psicóloga da instituição, Verônica sofreu o primeiro abuso sexual aos seis anos de idade. 0 estupro foi perpetrado pelo seu primo, filho desta tia com quem estava morando. Depois de ocorrida a violência, morar com a tia tornou-se insustentável, e Verônica, ainda com seis anos, passou a morar com Helena. Helena disse que mantinha uma boa relação com Verônica na época em que a mãe ainda era viva, assim, solicitou a guarda de Verônica por acreditar poder oferecer os cuidados que ela estava precisando. No entanto, após o tempo em que morou em Porto Alegre com a tia, Helena relatou que Verônica retornou rebelde, agressiva, uma criança "difícil de lidar", envolvia-se em diversas brigas com as crianças vizinhas e não a respeitava. Não conseguindo controlar a situação, Helena passou a agredir fisicamente Verônica. Com o tempo, Verônica cresceu, e Helena, não conseguindo mais agredi-la, pediu que seu marido passasse a fazê-lo. Verônica passou então a ser agredida constantemente e, não suportando a situação, fugiu da casa de sua irmã aos 10 anos de idade, permanecendo em situação de rua até a intervenção do Conselho 
Tutelar, que a encaminhou pela primeira vez para o acolhimento.

Ao saber da situação, Joana, segundo relato da psicóloga da instituição, tornou-se responsável por Verônica. Contudo, Verônica não se adaptou aos limites e a rotina da casa da avó e mudou-se para a casa de Mariana, sua irmã mais velha, sendo vítima de abuso sexual perpetrado pelo cunhado. Após a revelação da violência, Mariana e a família fugiram para o Ceará. Em situação de abandono, Verônica passou a morar com o pai de seus irmãos em Tocantins, por quem foi abusada sexualmente. Posteriormente, retornou à Santa Maria para morar novamente com a irmã Helena e o cunhado, onde foi abusada pelo sogro da irmã e então fugiu de casa aos doze anos. Em situação de rua e de exploração sexual, foi encontrada pelo Conselho Tutelar, que a encaminhou para a instituição onde permaneceu durante um ano e seis meses (segundo acolhimento). Durante esse acolhimento, recebeu visita apenas de Helena, que era obrigada a comparecer por causa de uma medida judicial solicitada pela coordenação da instituição de acolhimento. Após a coleta de dados, Verônica foi desligada da instituição de acolhimento e estava morando com Joana, mas, de acordo com a psicóloga Suzana, uma das filhas de Joana recorreu à instituição para pedir o retorno de Verônica por considerar que Joana não tinha condições de educá-la em casa por apresentar idade avançada e problemas de saúde.

A elaboração deste caso apenas foi possível através da triangulação dos dados obtidos nas três entrevistas, pois a participante não tinha recordações muito claras sobre os fatos ocorridos em sua vida, principalmente sobre a infância. Durante a entrevista, Verônica disse não se lembrar de muitos eventos, lembrava-se que "apanhava" muito e por isso era agressiva, mas disse não saber responder a respeito de sua família, respondendo apenas em relação a seu atual momento de vida. Nas questões que envolviam seu passado, ela pediu que as perguntas fossem feitas para os funcionários da instituição e afirmou que a equipe era quem saberia responder as questões sobre sua vida antes do acolhimento.

Do primeiro contato, no encontro em grupo, ao último, na entrevista, Verônica apresentou comportamentos ambivalentes. Inicialmente, se portava de maneira agressiva e intimidadora; posteriormente, tornava-se participativa, ativa e afetuosa, revelando com facilidade e iniciativa própria conteúdos relacionados aos motivos do acolhimento, os abusos sofridos e o medo do dia em que teria de sair definitivamente da instituição. Verônica considerava a instituição de acolhimento responsável por torná-la uma pessoa melhor, disse ter percebido esta mudança e ter ouvido isto de outras pessoas. Apresentava uma boa relação com a psicóloga da instituição, remetia-se a ela com carinho e respeito, demonstrando a existência de um vínculo entre elas. Da mesma forma, foi possível constatar reciprocidade de afeto por parte da psicóloga, que se referia à Verônica com carinho e buscava sua proteção e bem-estar.

\section{Discussão}

Os dados coletados através da inserção ecológica e das entrevistas possibilitaram a compreensão sobre o desenvolvimento do padrão de apego de Verônica. Os relatos adquiridos na pesquisa demonstraram a possibilidade de uma falha na interação inicial, uma falta de cuidados e investimentos maternos, apesar de esta primeira relação possuir um papel de grande importância na formação do apego, pois a qualidade do primeiro relacionamento da criança com o principal cuidador modelará seus futuros relacionamentos, criando modelos de funcionamento que afetam o comportamento das crianças que tendem a criar em cada novo relacionamento o padrão com que está familiarizada (Bowlby, 1990).

Durante sua infância, Verônica passou por diversos cuidadores e foi vítima de diversas formas de violência, como abuso sexual, abandono e agressões físicas perpetrados justamente por aqueles que deveriam protegê-la e ser sua figura de apego. Foram experiências que influenciaram a forma como Verônica se posicionava no mundo, como seu comportamento ambíguo, no qual ora agia de forma agressiva ora de forma afetuosa. Bowlby (1981) aponta que estes comportamentos são significativamente frequentes em indivíduos que sofreram abusos, e geralmente vêm acompanhados de ataque aos companheiros, provocações e ameaças de ataque às pessoas que realizam o cuidado, reação a aproximações amigáveis, evitando interação ou, ainda, por movimentos mistos de evitação e aproximação. Estas características compõem a dimensão 
pessoa do modelo bioecológico proposto por Bronfenbrenner e Morris (1998).

0 relato de aspectos de sua vida, como as experiências as quais foi submetida, são evidências que apontam que o apego desenvolvido durante a infância foi o padrão de apego inseguro resistente, no qual ocorre uma oscilação entre a busca de contato com sua mãe (ou principal figura de apego) e a resistência ao contato com esta, além de a pessoa mostrar-se mais colérica ou passiva que as que se encaixam em um dos outros padrões de apego existentes (Bowlby, 1990). As crianças avaliadas com apego inseguro provavelmente tiveram cuidadores "psicologicamente indisponíveis", apresentando um padrão de distanciamento ou negligência, aspectos presentes na história de Verônica. Os comportamentos de apego do tipo inseguro são comumente resultantes de cuidados precários ou de cuidados dispensados a crianças por uma sucessão de diferentes pessoas (Bowlby, 1981). Além disso, seu atual comportamento agressivo e ambíguo e a persistência nessa forma de relacionar-se evidenciam que o modelo de funcionamento interno estruturado a partir do padrão de apego inseguro resistente está presente até hoje, corroborando estudos que encontraram esse tipo de apego em adolescentes que moram em instituições (Dalbem \& Dell'Aglio, 2008; Hortacsu \& Cesur, 1993; Marcovitch et al., 1997).

Mesmo apresentando o padrão de apego inseguro resistente, Verônica, após ser acolhida institucionalmente, estava conseguindo desenvolver formas mais saudáveis de se relacionar, notando em si uma melhora, a qual atribuiu ao apoio que teve na instituição através da equipe técnica, do convívio com outras adolescentes e, principalmente, através do investimento realizado pela coordenadora do acolhimento e pela psicóloga. Apesar da tendência à persistência no padrão de apego construído na infância, existem provas de que estes padrões podem ser modificados por eventos que ocorrem em anos subsequentes (Dalbem \& Dell'Aglio, 2008). Mesmo que as crianças institucionalizadas tragam consigo a insegurança gerada pela falha da primeira relação para dentro da nova relação, elas também trazem a possibilidade de transformação, na qual o que não foi encontrado na relação primária possa ser buscado agora na instituição acolhedora (Cavalcante \& Jorge, 2008). Bowlby (1981) afirma que aquele que desempenha um papel de cuidado, mesmo que de forma provisória e substituta, minimiza os efeitos nocivos da privação, pois possibilita a existência de uma relação afetiva, contribuindo para a saúde mental das crianças. Assim, a instituição de acolhimento mostra-se como um espaço destinado ao cuidado das crianças e dos adolescentes e um possível propulsor de mudanças e melhoramentos destes enquanto sujeitos. Estudos têm demonstrado a importância da equipe dos acolhimentos para a adaptação das crianças e dos adolescentes, bem como para superação dos traumas (Bazon \& Biasoli-Alves, 2000). De acordo com Cavalcante e Jorge (2008) e Junqueira e Deslandes (2003), a relação estabelecida com os monitores desempenha papel central na vida das crianças e dos adolescentes que vivenciaram violência e rupturas de vínculos afetivos na infância, à medida que serão estes que assumirão a função de orientá-los e protegê-los, constituindo, neste momento, seus modelos identificatórios. Além disso, segundo pesquisa desenvolvida por Pasian e Jacquemin (1999), o contato da criança com uma estrutura institucional de qualidade propicia experiências de vida positivas, podendo favorecer a diminuição do número de sinais de dificuldades emocionais.

Bronfenbrenner (1979/1996) destacava a influência dos contextos de interação para o desenvolvimento do ser humano. Pode-se constatar a existência de dois microssistemas centrais para a adolescente: sua família e a instituição de acolhimento. 0 microssistema familiar constitui-se no primeiro contexto no qual uma criança interage, tendo fundamental influência para seu desenvolvimento. Contudo, apesar de ter havido tentativas de proteção por parte de seus familiares diante da constatação da violência, Verônica foi afastada dos agressores. As sucessivas experiências de violência demonstraram que ela não teve muitas chances de superar o sofrimento anterior e sentir-se acolhida na família, sendo que foi preciso escolher a rua para se afastar da violência. Além disso, sua irmã somente mantinha contato com Verônica porque era obrigada judicialmente. Pode-se concluir que a relação da adolescente com sua família de origem não gerava processos proximais. Por outro lado, seu segundo microssistema central, a instituição de acolhimento, estava proporcionando uma rotina, convivência saudável com outros adultos e crianças, além de atender as suas necessidades básicas de alimentação, moradia, saúde, educação e lazer. Os relatos da própria adolescente e da psicóloga e os dados 
advindos da inserção ecológica demonstraram que a instituição estava investindo na adolescente, algo que sua família não fazia. As relações e atividades desenvolvidas nos diversos microssistemas são fundamentais para que os processos proximais possam surgir e levar ao desenvolvimento (Bronfenbrenner, 2005). Constatou-se a presença no microssistema institucional de aspectos fundamentais para o surgimento de processos proximais, como reciprocidade, regularidade e frequência das atividades, operando mudanças e desenvolvimento.

\section{Considerações finais}

A análise do caso de Verônica forneceu elementos para a compreensão do apego na adolescência. A partir da apresentação dos resultados obtidos na pesquisa, foi possível confirmar a importância da relação primária para a formação do apego, considerando que estes padrões estão intimamente ligados aos cuidados oferecidos pela primeira figura de apego. Por causa dos relatos das formas de cuidado oferecidas à participante, cuidados precários e com a instabilidade de cuidadores a que ela foi submetida, pode-se inferir que ela desenvolveu na infância o padrão de apego do tipo inseguro resistente, comumente encontrado em pessoas que apresentam histórico de negligência e violência na infância.

Atualmente, observou-se que este padrão de apego desenvolvido tem se repetido, evidenciando que a participante possuía, no momento da pesquisa, o mesmo tipo de apego da infância, o apego inseguro. À medida que os anos passam, há uma maior probabilidade de o padrão de apego desenvolvido se estabilizar e tornar-se cada vez mais rígido. Contudo, a partir do fato de verbalizar as mudanças positivas que tem vivenciado a partir do investimento afetivo do acolhimento institucional, em especial do vínculo estabelecido com a psicóloga e com a coordenadora da instituição de acolhimento, pode-se vislumbrar que, mesmo que haja uma tendência à estabilidade, Verônica pode desenvolver outros tipos de apego mais positivos e saudáveis. De fato, constatou-se a ocorrência de processos proximais no microssistema institucional, os quais não estavam presentes na relação com sua família. 0 apego desenvolvido não se constitui em uma condição definitiva, o que mostra a possibilidade de mudanças. Este dado demonstra a importância dos educadores e da equipe técnica estar ciente de sua influência nos jovens institucionalizados, tendo em vista que podem atuar como fonte de apoio e alicerce para a construção de relações interpessoais mais saudáveis. Estas relações no cotidiano irão desconstruir o "Modelo Interno" e possibilitarão que processos de resiliência se manifestem. Assim, sugere-se que intervenções voltadas às equipes técnicas e aos educadores das instituições sejam realizadas para que se possam potencializar os efeitos positivos de relacionamentos saudáveis.

As características do delineamento do estudo - estudo de caso único e transversal - podem ser consideradas limitações da presente pesquisa. A inclusão de mais casos poderia fornecer dados que demonstrassem as semelhanças e as diferenças no fenômeno. Da mesma forma, a realização de mais entrevistas distribuídas em um período maior transformaria este estudo em longitudinal e possibilitaria que fossem identificadas mudanças na trajetória de vida de Verônica, analisando a dimensão tempo do modelo bioecológico. Mesmo perante estas limitações, o caso apresentou riqueza para atingir o objetivo do estudo. Torna-se necessário fomentar os estudos sobre desenvolvimento da representação de apego em adolescentes institucionalizados, considerando a escassez de estudos atuais para que políticas de atenção a estes jovens possam ser construídas. É tempo de voltar a atenção ao desenvolvimento do apego de jovens afastados de suas famílias de origem para que eles possam superar esta trajetória de rupturas e construir relações futuras.

\section{Referências}

Abaid, J. W. L., Siqueira, A. C., \& Dell'Aglio, D. D. (2012). Implicações legais e desenvolvimentais no acolhimento institucional: Possibilidades e desafios numa perspectiva psicológica. In D. M. Arpini \& A. C. Siqueira (Orgs.), Família e Leis: Desafios à realidade brasileira (pp. 71-102). Santa Maria: UFSM.

Alexandre, D. T., \& Vieira, M. L. (2004). Relação de apego entre crianças institucionalizadas que vivem em situação de abrigo. Psicologia em Estudo, 9(2), 207-217.

Bazon, M. R, \& Biasoli-Alves, Z. M. M. (2000). A transformação de monitores em educadores: uma questão de desenvolvimento. Psicologia: Reflexão e Crítica, 13(1), 199-204. 
Bowlby, J. (1981). Cuidados maternos e saúde mental. São Paulo: Martins Fontes.

Bowlby, J. (1990). Apego e perda. São Paulo: Martins Fontes.

Brasil. (1990). Lei №. 8069, de 13 de julho de 1990. Estatuto da criança e do adolescente. Diário Oficial da União. Brasília.

Brasil. (1997). Resolução 196/96, de 10 de outubro de 1996. Conselho Nacional de Saúde, Comitê de Ética em Pesquisa em Seres Humanos: diretrizes e normas regulamentadoras de pesquisas envolvendo seres humanos. Ministério da Saúde, Brasília.

Brasil. (2009). Nova Lei Nacional da Adoção. Lei $\mathrm{n}$ o 12.010, de 3 de agosto. Brasília, DF. Recuperado em 9 de março de 2010, de http://www.planalto.gov.br/ ccivil_03/_Ato2007-2010/2009/Lei/L12010.htm

Bronfenbrenner, U. (1986). Ecology of the family a context for human development: Research perspectives. Developmental Psychology, 32(6), 723-742.

Bronfenbrenner, U. (1996). A ecologia do desenvolvimento humano: Experimentos naturais e planejados (M. A. V. Veronese, trad.). Porto Alegre: Artes Médicas (Original publicado em 1979).

Bronfenbrenner, U. (1999). Environments in developmental perspective: Theorical and operational models. In S. L. Friedmann \& T. D. Wacks (Eds.), Measuring environment across the life span: Emerging methods and concepts (pp.3-30). Washington, DC: American Psychological Association.

Bronfenbrenner, U. (2005). The bioecological theory of human development. In U. Bronfenbrenner (Ed.), Making human beings human: Bioecological perspectives on human development. (pp.3-15). Thousand Oaks: Sage.

Bronfenbrenner, U., \& Ceci, S. J. (1994). Nature-nurture reconceptualized in developmental perspective: A bioecological model. Psychological Review, 101, 568-586.

Bronfenbrenner, U., \& Evans, G. (2000). Developmental science in the $21^{\text {st }}$ century: Emerging questions, theoretical models, research designs and empirical findings. Social Development, 9, 115-125.
Bronfenbrenner, U., \& Morris, P. (1998). The ecology of developmental processes. In W. Damon (Ed.), Handbook of child psychology (pp. 993-1027). Nova York: John Wiley \& Sons.

Carvalho, A. M. (2002). Crianças institucionalizadas e desenvolvimento: possibilidades e desafios. In E. $\mathrm{R}$ Lordelo, A. M. Carvalho \& S. H. Koller, (Orgs.), Infância brasileira e contextos de desenvolvimento (pp.19-44). São Paulo: Casa do Psicólogo.

Cavalcante, C. M., \& Jorge, M. S. B. (2008). Mãe é a que cria: o significado de uma maternidade substituta. Estudo Psicologia, 25(2), 265-267.

Cecconello, A. M., \& Koller, S. H. (2003). Inserção ecológica na comunidade: Uma proposta metodológica para o estudo de famílias em situação de risco. Psicologia: Reflexão e Crítica, 16(3), 515-524.

Dalbem, J. X, \& Dell'Aglio, D. D. (2008). Apego em adolescentes institucionalizadas: processos de resiliência na formação de novos vínculos afetivos. Psico, 39(1), 33-40.

Dalbem, J. X. (2005). Características da representação do apego em adolescentes institucionalizadas e processos de resiliência na construção de novas relações afetivas. Dissertação de Mestrado. Programa de PósGraduação em Psicologia. Universidade Federal do Rio Grande do Sul, Porto Alegre: UFRGS.

Dell'Aglio, D. (2000). O processo de coping, institucionalização e eventos de vida em crianças e adolescentes. Tese de Doutorado. Programa de Pós-Graduação em Psicologia do Desenvolvimento. Universidade Federal do Rio Grande do Sul, Porto Alegre: UFRGS.

Dell'Aglio, D. D., \& Hutz, C. S. (2002). Estratégias de coping de crianças e adolescentes em eventos estressantes com pares e com adultos. Psicologia USP, 13(2), 203-225.

Dell'Aglio, D. D., \& Hutz, C. S. (2004). Depressão e desempenho escolar em crianças e adolescentes institucionalizados. Psicologia: Reflexão e Crítica, 17(3), 351-357.

Ferreira, L. A. M., Dói, C. K. T., \& Baldacim, E. (2009). Quadro comparativo ECA e a Lei № 12.010/09. Artigo 38. Recuperado em 9 de janeiro de 2012, de http:// www.pjpp.sp.gov.br/2004/artigos/42.pdf. 
Hortacsu, N., \& Cesur, S. (1993). Relationships between depression and attachment styles in parent and institution-reared Turkish children. Journal of Genetic Psychology, 154, 329-337.

Junqueira, M. F. P, \& Deslandes, S. F. (2003). Resiliência e maus-tratos à criança. Caderno de Saúde Pública, 19(1), 227-235.

Marcovitch, S., Goldberg, S., Gold, A., Washington, J., Wassom, C., Krekewich, K., et al. (1997). Determinants of behavioral problems in Romanian children adopted in Ontario. International Journal of Behavioural Development, 20, 17-31.

Martins, E., \& Szymanski, H. (2004). Brincando de casinha: significado de família para crianças institucionalizadas. Estudos de Psicologia (Natal), 9(1), 177-187.

Mota, C. P., \& Matos, P. M. (2008). Adolescência e institucionalização numa perspectiva de vinculação. Psicologia \& Sociedade, 20(3), 367-377.

Oriente, I, \& Souza, S. M. G. (2005). O significado do abandono para crianças institucionalizadas. Psicologia em Revista, 11(17), 29-46.

Pasian, S. R., \& Jacquemin, A. (1999). 0 autorretrato em crianças institucionalizadas. Paidéia, 9(17), 50-60.

Pereira, M., Soares, I., Dias, P., Silva, J., Marques, S., \& Baptista, J. (2010). Desenvolvimento, psicopatologia e apego: estudo exploratório com crianças institucionalizadas e suas cuidadoras. Psicologia: Reflexão e Crítica, 23(2), 222-231.
Prada, C. G., Williams, L. C. A., \& Weber, L. N. D. (2007). Abrigos para crianças vítimas de violência doméstica: funcionamento relatado pelas crianças e pelos dirigentes. Psicologia: Teoria e Prática, 9(2), 14-25.

Prati, L. E., Couto, M. C. P., Moura, A., Poletto, M., \& Koller, S. H. (2008). Revisando a inserção ecológica: uma proposta de sistematização. Psicologia: Reflexão \& Crítica, 21(1), 160-169.

Roig, A. M., \& Ochotorena, J. P. (1993). Maltrato y abandono en la infancia. Barcelona: Martinez Roca.

Silva, E. R. (2004). O direito à convivência familiar e comunitária: Os abrigos para crianças e adolescentes no Brasil. Brasília: IPEA/CONANDA.

Siqueira, A. C., \& Dell'Aglio, D. D. (2006). 0 impacto da institucionalização na infância e na adolescência: uma revisão de literatura. Psicologia \& Sociedade, 18(1), 71-80.

Siqueira, A. C., Spath, R., Dell'Aglio, D. D., \& Koller, S. H. (2011). Multidimensional life satisfaction, stressful events and social support network of Brazilian children in out-of-home care. Child \& Family Social Work, 16, 111-120.

Vectore, C., \& Carvalho, C. (2008). Um olhar sobre o abrigamento: A importância dos vínculos em contexto de abrigo. Psicologia Escolar e Educacional, 12(2), 441-449.

Yin , R. K. (2005). Estudo de caso: Planejamento e métodos. (Daniel Grassi, trad.). Porto Alegre: Bookman. (Original publicado em 2003). 